\title{
Metformin: historical overview
}

\author{
Clifford J. Bailey ${ }^{1}$
}

Received: 14 March 2017 / Accepted: 10 May 2017 /Published online: 3 August 2017

(C) Springer-Verlag Berlin Heidelberg 2017

\begin{abstract}
Metformin (dimethylbiguanide) has become the preferred first-line oral blood glucose-lowering agent to manage type 2 diabetes. Its history is linked to Galega officinalis (also known as goat's rue), a traditional herbal medicine in Europe, found to be rich in guanidine, which, in 1918, was shown to lower blood glucose. Guanidine derivatives, including metformin, were synthesised and some (not metformin) were used to treat diabetes in the 1920s and 1930s but were discontinued due to toxicity and the increased availability of insulin. Metformin was rediscovered in the search for antimalarial agents in the 1940s and, during clinical tests, proved useful to treat influenza when it sometimes lowered blood glucose. This property was pursued by the French physician Jean Sterne, who first reported the use of metformin to treat diabetes in 1957. However, metformin received limited attention as it was less potent than other glucose-lowering biguanides (phenformin and buformin), which were generally discontinued in the late 1970s due to high risk of lactic acidosis. Metformin's future was precarious, its reputation tarnished by association with other biguanides despite evident differences. The ability of metformin to counter insulin resistance and address adult-onset hyperglycaemia without weight gain or increased risk of hypoglycaemia gradually gathered credence in Europe, and after intensive scrutiny metformin was introduced into the USA in 1995. Long-term cardiovascular benefits of metformin were identified by the UK Prospective
\end{abstract}

Electronic supplementary material The online version of this article (doi:10.1007/s00125-017-4318-z) contains a slideset of the figures for download, which is available to authorised users

Clifford J. Bailey

c.j.bailey@aston.ac.uk

1 School of Life and Health Sciences, Aston University, Gosta Green, Birmingham B4 7ET, UK
Diabetes Study (UKPDS) in 1998, providing a new rationale to adopt metformin as initial therapy to manage hyperglycaemia in type 2 diabetes. Sixty years after its introduction in diabetes treatment, metformin has become the most prescribed glucose-lowering medicine worldwide with the potential for further therapeutic applications.

Keywords Biguanide $\cdot$ Dimethylbiguanide $\cdot$ Galega officinalis · Guanidine · History · Jean Sterne · Metformin . Review · Type 2 diabetes
Abbreviations
FDA Food and Drug Administration
IFG Impaired fasting glucose
IGT Impaired glucose tolerance
UKPDS UK Prospective Diabetes Study

\section{Introduction}

This short biography of metformin (1,1-dimethylbiguanide hydrochloride) plots a chequered history from herbal ancestry in Europe to synthesis, and the discovery of its glucoselowering activity in the 1920s: information that was disregarded and forgotten. In the 1940s, metformin was rediscovered in the search for antimalarial agents and repurposed to treat influenza, before its introduction, in 1957, for the treatment of adult-onset diabetes (Table 1). However, metformin was considered weaker than other glucose-lowering biguanides and received limited use. When the other biguanides (phenformin and buformin) were withdrawn in the late 1970s because of links to lactic acidosis, metformin was spared, but mostly rejected. However, ongoing research and minimal clinical use in the 1980s and early 1990s 
Table 1 Landmark events in the history of metformin for the management of type 2 diabetes

\begin{tabular}{|c|c|c|}
\hline Year & Landmark & Reference \\
\hline 1772 & Galega officinalis used to treat symptoms of diabetes (Hill) & [3] \\
\hline $1844-1861$ & Identification and synthesis of guanidine (Strecker) & {$[6]$} \\
\hline $1878-1879$ & Synthesis of biguanide (Rathke) & {$[6]$} \\
\hline 1918 & Guanidine lowers blood glucose in animals (Watanabe) & {$[7]$} \\
\hline 1922 & Synthesis of dimethylbiguanide (Werner and Bell) & [17] \\
\hline $1926-1928$ & Galegine and synthalin lower blood glucose in animals and humans & {$[8-13]$} \\
\hline 1929 & Metformin and other biguanides lower blood glucose in animals (Hesse and Taubmann; Slotta and Tschesche) & {$[18,19]$} \\
\hline $1930 \mathrm{~s}$ & $\begin{array}{l}\text { Use of guanidine derivatives to treat diabetes initially grows then declines due to toxicity and also availability } \\
\text { of insulin }\end{array}$ & {$[6]$} \\
\hline 1944-1947 & Guanidine-based antimalarial agent, proguanil (Paludrine), lowers blood glucose in animals & {$[20,21]$} \\
\hline $1949-1950$ & $\begin{array}{l}\text { Dimethylbiguanide (flumamine) tested as potential antimalarial agent and used to treat influenza in Philippines. } \\
\text { Also found to potentially lower blood glucose (Garcia) }\end{array}$ & {$[22]$} \\
\hline 1956 & Jan Aron encourages Jean Sterne and Denise Duval to study guanidine-based glucose-lowering agents & {$[6]$} \\
\hline 1957 & Jean Sterne publishes use of metformin to treat diabetes & {$[24]$} \\
\hline $1957-1959$ & Phenformin and buformin reported as treatments for diabetes & {$[32,33,37,38]$} \\
\hline 1958 & Metformin introduced to treat diabetes in the UK and other European countries & {$[6]$} \\
\hline $1958-1964$ & Sterne and colleagues (especially Azerad) further evaluate metformin in individuals with diabetes & {$[25-28,36]$} \\
\hline 1968 & First large prospective comparator trial of metformin (Edinburgh, UK; notably Duncan, Clarke and Campbell) & [42] \\
\hline $1977-1980$ & Phenformin and buformin withdrawn in most countries because of risk of lactic acidosis & [49] \\
\hline 1980-1994 & $\begin{array}{l}\text { Substantial new scientific and clinical evidence (e.g. Hermann, Noel, Wiernsperger and Bailey), strategic input } \\
\text { by Lipha pharmaceuticals (e.g. Howlett, Meynaud, Daniel, Goodman) and discussions with the FDA } \\
\text { (Reaven, DeFronzo, Bailey, Turner, Garber) }\end{array}$ & {$[6,41,44,56-62]$} \\
\hline 1994-1995 & Metformin approved (1994) and introduced (1995) in the USA & {$[6]$} \\
\hline 1995-1996 & Key publications confirm favourable benefit:risk ratio of metformin in management of T2D & {$[63,64]$} \\
\hline $1995-2000$ & Extensive diabetes education programme by Bristol-Myers Squibb (e.g. Cryer) & {$[6]$} \\
\hline 1998 & UKPDS reports long-term metabolic effects of metformin and reduced cardiovascular risk with use & [69] \\
\hline $2000-2002$ & $\begin{array}{l}\text { Extended-release formulation and fixed-dose combination drugs with metformin as the primary active } \\
\text { ingredient are approved in the USA }\end{array}$ & {$[65,67]$} \\
\hline 2002 & Metformin reduced progression of 'prediabetes' (IGT and/or IFG) to T2D in the DPP & [82] \\
\hline 2005 & $\begin{array}{l}\text { The IDF recommends metformin as an initial glucose-lowering pharmacotherapy for T2D. Other } \\
\text { guidelines adopt metformin as an initial glucose-lowering agent }\end{array}$ & {$[75]$} \\
\hline 2008 & UKPDS follow-up: continued reduction of cardiovascular risk with use of metformin (Holman) & {$[74]$} \\
\hline 2011 & Metformin included in WHO's essential medicines list & [79] \\
\hline
\end{tabular}

DPP, Diabetes Prevention Program; IDF, International Diabetes Federation; T2D, type 2 diabetes; WHO, World Health Organization

demonstrated a uniqueness and utility of metformin that fostered its rescue. The introduction of metformin into the USA in 1995 boosted research and clinical use and long-term evidence from the UK Prospective Diabetes Study (UKPDS) in 1998 set metformin on course for its current position as the preferred initial agent to manage hyperglycaemia in type 2 diabetes. Now exonerated, metformin is being assessed for further clinical indications. How could such a medicinal servant have received such a tempestuous journey?

\section{Herbal history}

The herbal lineage of metformin can be traced from the use of Galega officinalis (a.k.a. goat's rue, French lilac, Italian fitch,
Spanish sainfoin or professor weed; Fig. 1) as a traditional medicine in medieval Europe [1]. Also known as Herba rutae caprariae in some herbals, G. officinalis was ascribed benefits against worms, epilepsy ('falling-sickness'), fever and pestilence in Culpeper's Complete Herbal of 1653, whilst in 1772, John Hill recommended Galega to treat conditions of thirst and frequent urination [2-4]. In Europe, wild G. officinalis was widely recognised as an animal galactagogue from which it gained its name ('Galega' being derived from the Greek for 'milk stimulant'). The plant was introduced into North America in 1891 and is now classed as a noxious weed in many states of the USA [5]. Chemical analyses of $G$. officinalis dating from the mid-1800s found the plant to be rich in guanidine and related compounds (shown in Fig. 2), especially the immature seed pods [6]. In 1918, guanidine was 


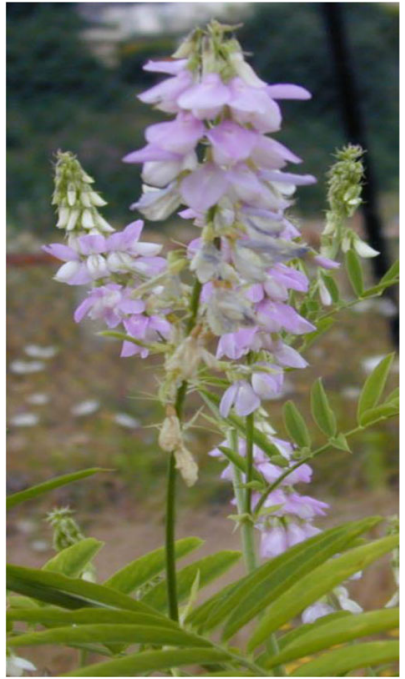

Fig. 1 Galega officinalis. G. officinalis, the herbal lineage of metformin, is also known as goat's rue, French lilac, Italian fitch, Spanish sainfoin or professor weed. This plant was used as a traditional medicine in medieval Europe; it is now classed as a noxious weed in many states of the USA. Copyright Malcolm Storey, www.bioimages.org.uk (photograph taken in Berkshire, UK, 1 July 2000)

reported to reduce blood glucose in animals, and during the 1920s several mono-guanidine derivatives, notably galegine (isoamylene guanidine) and diguanidines, such as synthalin (two guanidines separated by a methylene chain; see Fig. 2), were also shown to lower blood glucose in animals [6-10]. This led to the introduction of galegine and the more potent synthalin in diabetes treatment. However, initial optimism was tempered with disappointment as toxicity was observed, curtailing their use during the 1930s as insulin became more widely available $[6,11-15]$.

\section{From Galega to biguanides}

The chemical origins of metformin run in parallel with its herbal origins and date from the preparation of guanidine by Adolph Strecker (1840s-1860s) and the subsequent work of Bernhard Rathke in 1879, resulting in the fusion of two guanidines to form biguanide (Fig. 2) $[6,16]$. These developments provide the background for the synthesis of metformin (dimethylbiguanide) by Werner and Bell in 1922 [17]. Despite structural proximity to the glucose-lowering mono- and diguanidines, it was not until 1929 that metformin and other biguanides were reported to lower blood glucose levels in animals (rabbits and dogs) by Hesse and Taubmann and Slotta and Tschesche [18, 19]. Importantly, biguanides were deemed to be less toxic than mono- and diguanidines and, of the various methyl biguanides tested, metformin exerted the least toxicity [19]. However, the real potential of these agents was underappreciated at the time because of the high doses required to achieve modest glucose-lowering effects in non-diabetic animals (compared with subsequent evidence in models of diabetes). Hence, the biguanides were not developed for diabetes therapy and were forgotten during the following decade, along with the other guanidine-based agents.

\section{Rediscovery via malaria and influenza}

A third strand in the history of metformin is the independent development of a guanidine-based antimalarial agent proguanil (Paludrine) in the mid 1940s. This drug was reported to cause a lowering of blood glucose in animal studies [20,21]. In a search for other guanidine-based antimalarials, proguanil was modified to metformin, and tests for antimalarial activity by Eusebio Garcia in the Philippines, in 1949, found metformin to be helpful in treating a local influenza outbreak [22]. This gave rise to the use of metformin hydrochloride as an anti-influenza agent called flumamine, and a tendency for metformin to lower blood glucose in some of the influenza patients was duly noted [6, 22].

\section{Step forward Jean Sterne}

The visionary who translated the blood-glucose lowering potential of metformin into a therapeutic reality was Jean Sterne, a physician at the Aron Laboratories in Suresnes, in the west of Paris, France (Fig. 3). In 1956, encouraged by laboratory owner, Jan Aron, Sterne critically assessed the evidence around flumamine, and recalled his involvement in a disappointing study of galegine as an intern with Professor Francis Rathery at Hôpital de la Pitié in Paris many years earlier [23]. Maybe metformin would be better? Working at Aron Laboratories with his pharmacist colleague, Denise Duval, the duo embarked on an ambitious programme of research into the pharmacodynamics of several guanidine-based compounds, including metformin and phenformin, in normal and diabetic animal models. Unknowingly they duplicated and extended studies on guanidine-based compounds from the 1920s and noted afresh the issues of high dose, limited glucose-lowering properties and high toxicity. They singled out metformin for study in the diabetes clinic based on its glucose-lowering efficacy and minimal adverse effects in normal and diabetic animal models, coupled with the documented experience of flumamine use in humans [6].

Sterne had a position at Hôpital Laennec in Paris where he started metformin studies with his patients; he also persuaded Dr. Elie Azerad at Hôpital Beaujon in Clichy (northwestern Paris) to collaborate. Their initial studies, mostly in insulintreated individuals, included a mix of juvenile-onset and maturity-onset presentations of diabetes. The studies indicated that metformin could replace the need for insulin in some individuals with maturity-onset diabetes and reduce the insulin dose required by others, but it did not eliminate the need for 


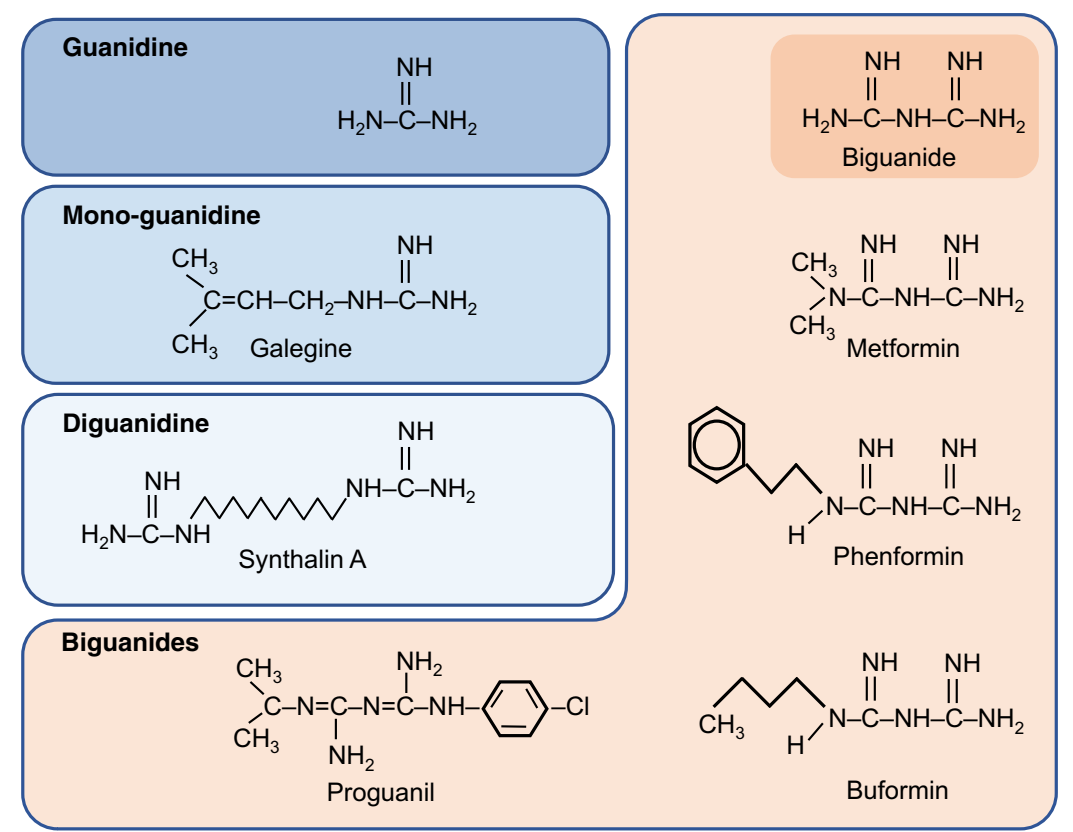

Fig. 2 Structure of guanidine and related compounds. G. officinalis is rich in guanidine, which is known to reduce blood glucose levels in animals. Some mono-guanidine (e.g. galegine) and diguanidine (e.g. synthalin) derivatives have blood glucose-lowering properties, as do biguanides (formed via fusion of two guanidine molecules) and their derivatives (metformin, phenformin, buformin and proguanil).

insulin in individuals with juvenile-onset diabetes [6]. They also noted no occurrence of frank hypoglycaemia (as had recently been reported with sulfonylureas) and little or no effect of metformin use in individuals without diabetes. This was enough for Sterne to publish a brief account of his findings in a Moroccan medical journal in 1957 [24], a paper that is

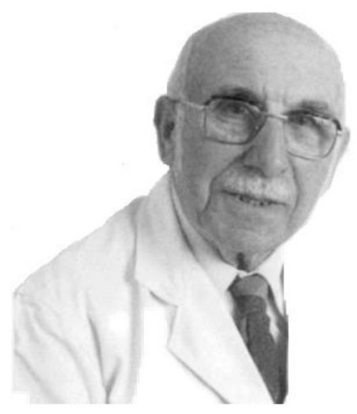

Fig. 3 Jean Sterne (1909-1997). Jean Sterne trained in medicine in Paris and gained experience in diabetology with Francis Rathery at Hôpital de la Pitié, as well as taking specialisms in infectious diseases, cardiology, psychiatry and neurology. During the second world war, he was a battalion medic; he was taken prisoner, escaped to Morocco where he worked as a musician, and later returned to France to assist in the liberation of Toulouse. In 1956, after several years of being back in Morocco, directing the medicines unit at a hospital in Casablanca, Sterne took a position with Aron Laboratories in Suresnes, Paris. Here he investigated guanidine derivatives with Denise Duval. The rest, as they say, is history. At the end of an interview in 1996, Sterne commented, 'When I look back on my life, I definitely can say that I've served a purpose on Earth'. Metformin is his testament [23]. Photograph courtesy of Christophe Pasik, MerckLipha Pharmaceuticals (Lyon, France)
However, the mono- and diguanidine derivatives proved to be too toxic for continued clinical use, while phenformin and buformin were discontinued in most countries because of increased risk of lactic acidosis; only metformin is widely approved for use as a glucose-lowering agent in the management of type 2 diabetes

now recognised as a landmark paper for the emergence of metformin as a diabetes therapy. In his report, Sterne made the following prophetic remarks (translated from French): 'LA6023 [metformin] is...well tolerated, which, even after very prolonged administration, does not damage the organism. At low doses, it is hypoglycaemic by mouth in the rabbit, chicken, rat, guinea pig, dog, alloxan-diabetic rabbit, and the diabetic human... and its ultimate place in the management of diabetes requires further study'. Later publications would elaborate details of these animal studies, revealing Sterne's insight, skill and persistence [25-31].

Sterne suggested the name 'glucophage' (meaning glucose eater), which was adopted by Aron to market metformin, and Sterne played a prominent role in ongoing research and physician education to assist the introduction of metformin into clinical practice in Europe [6]. History might be tempted to consider the diabetes indication of metformin as serendipitous, but we must gratefully acknowledge Sterne's sharp enquiring mind, his prodigious experimentation and his perceptive clinical sixth sense.

\section{The biguanide opportunity}

During the 1950s, other groups investigated guanidine derivatives, and the glucose-lowering properties of phenformin were rediscovered and published in 1957 by Ungar and colleagues (based in the USA) [32]. This was followed by reports 
of buformin's ability to reduce blood sugar levels in 1958, by A. Beringer (Germany) [32, 33]. A vast selection of guanidine derivatives was then synthesised and evaluated, but enthusiasm was dampened by their lesser glucose-lowering efficacy in non-diabetic animals compared with agents that stimulate insulin secretion [34, 35]. However, studies in human maturity-onset diabetes indicated greater glucose-lowering efficacy of phenformin compared with other biguanides and this agent gained global popularity as an alternative to sulfonylureas, especially in the USA [36-38]. At this time, metformin and buformin were not introduced for use in the USA and received relatively minor use in Europe, although metformin became available in the UK in 1958 and in Canada in 1972 and was championed in several respected diabetes clinics. In the early 1960s, buformin became available across Europe (but not the UK), with its use particularly being adopted in Germany; nonetheless, it remained in the shadow of phenformin $[39,40]$.

Clinical experience with metformin use in small studies and anecdotal accounts from individuals with maturity-onset diabetes typically portrayed modest efficacy but generally good tolerability, accepting the gastrointestinal incommode experienced by some patients $[6,41]$. Large comparative trials (notably in Edinburgh, UK) showed that metformin could achieve similar long-term glycaemic control as sulfonylureas, without significant hypoglycaemia or weight gain [42-44]. Later studies reported that basal insulin concentrations were often reduced with metformin use, consistent with the amelioration of insulin resistance, while lipid-lowering effects and improved haemodynamics were evident in some individuals $[41,45]$. The requirement for renal monitoring was consolidated, contraindications were appreciated and a possible decrease of vitamin $\mathrm{B}_{12}$ absorption was recognised [41, 45].

\section{Lactic acidosis}

The risk of lactic acidosis, especially with phenformin and buformin, was evident from the outset, and the controversy was fuelled when phenformin was withdrawn from the University Group Diabetes Program (UGDP) trial in the USA in 1971 [46-48]. Phenformin was removed from the market in the USA in 1978, and phenformin and buformin were discontinued in much of Europe around this time, although both agents can still be obtained in some countries [49]. The incidence of lactic acidosis amongst users of metformin was much lower and most cases could be attributed to inappropriate use in contraindicated patients with chronically impaired renal function or in those with acute kidney disease $[47,50,51]$. Moreover, in some studies it was debatable whether incidence rates of lactic acidosis with metformin were higher than background rates amongst individuals with maturity-onset diabetes. Nevertheless, the reputation of metformin was tarnished by association with the other biguanides, causing metformin to teeter on the very brink of discontinuation [49].

Ironically, soon after withdrawal of phenformin it was noted that about $9 \%$ of Europids have a mutation in the CYP2D6 gene, encoding the cytochrome P450 2D6 (CYP2D6) hydroxylation enzyme, causing a build-up of unmetabolised phenformin, leading to lactic acidosis [52, 53]: a problem that modern pharmacogenomics could deal with.

\section{How did metformin survive the biguanide cull?}

Clinical experience with metformin, albeit limited compared with phenformin, generally suggested a more favourable safety profile, and there were pharmacokinetic data to indicate distinct differences between metformin and the other biguanides (Fig. 4; Table 2) [40, 41]. During the 1980s, 'non-insulin-dependent diabetes' (replacing the term 'maturity-onset diabetes'), as a condition, became viewed as much from the perspective of insulin resistance as beta cell failure, and the ability of metformin to counter insulin resistance generated interest $[54,55]$. New information in the 1980s and early 1990s indicated that the ability of metformin to reduce hepatic gluconeogenesis and increase peripheral glucose utilisation was not merely an anaerobic consequence of respiratory-chain disruption [45]. Rather, metformin affected a raft of insulin-dependent and insulin-independent effects in ways that varied in different tissues because of the difference in the amount of drug exposure to these tissues and the activity of insulin, glucagon and pathways of nutrient metabolism within these tissues. In particular, it became evident that high levels of metformin in the intestinal wall exert insulinindependent effects that account for most of the excess lactate production associated with its use, whereas liver and muscle tissues are exposed to lower concentrations of metformin that alter post-receptor insulin signalling pathways and redirect energy-generating and storage pathways [56-62].

\section{Metformin enters the USA}

With reverberations from phenformin, the US Food and Drug Administration (FDA) was hesitant about metformin, but in 1986 an approach by Lipha Pharmaceuticals (having acquired Aron Laboratories) sparked an inordinately thorough reassessment of metformin by the FDA and the sponsor. The Lipha team was led by Dr. Gerard Daniel, an inspired, meticulous and pragmatic physician reminiscent of Jean Sterne. Daniel worked tirelessly alongside another very accomplished physician, Dr. Anita Goodman, to deliver answers to an avalanche of questions from the FDA [6]. This involved a proliferation of studies by Lipha Europe plus input from a group of 


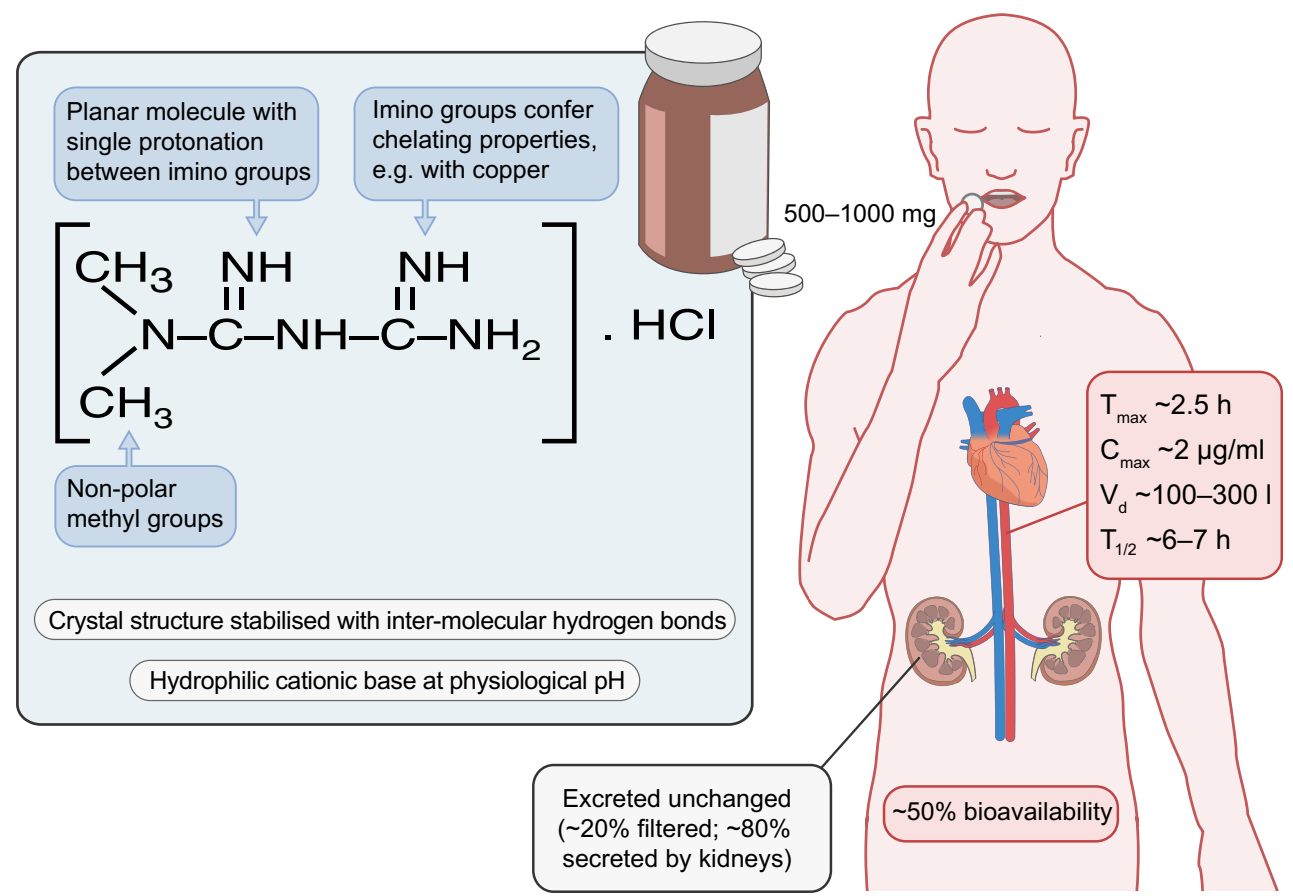

Fig. 4 Metformin structure and pharmacokinetics. Metformin $(1,1-$ dimethylbiguanide hydrochloride) is a relatively planar hydrophilic molecule, monoprotonated at neutral $\mathrm{pH}$ with several tautomeric configurations. Oral doses of 500 to $1000 \mathrm{mg}$ of the standard immediate-release tablet formulation are rapidly absorbed in the small intestine (time for drug to reach maximum plasma concentration after administration $\left(\mathrm{T}_{\max }\right), \sim 2.5 \mathrm{~h}$; approximately $50 \%$ bioavailability), typically giving a peak plasma concentration $\left(\mathrm{C}_{\max }\right)$ of about $2 \mu \mathrm{g} / \mathrm{ml}$, and rarely

independent clinical scientists (initially Gerald Reaven, Ralph DeFronzo and Clifford Bailey, later joined by Robert Turner and Alan Garber) who engaged with the FDA to design the clinical trials, discuss the data and consider the implications for routine clinical use in the USA $[6,56]$. The FDA approved
$>4 \mu \mathrm{g} / \mathrm{ml}$, with a steady-state concentration range of $0.3-1.5 \mu \mathrm{g} / \mathrm{ml}$. Plasma protein binding is negligible and distribution is extensive (usual volume of distribution $\left.\left[\mathrm{V}_{\mathrm{d}}\right], 100-3001\right)$. Metformin has an elimination half-life $\left(\mathrm{T}_{1 / 2}\right)$ of $\sim 6-7 \mathrm{~h}$, or longer if renal function is impaired. It is not metabolised and is excreted in the urine unchanged, with approximately $20 \%$ of the drug being filtered, with the remaining $\sim 80 \%$ being secreted by the kidney [92]

metformin on 29 December 1994 and soon after its launch in the USA, in 1995, new key trial data were published in the New England Journal of Medicine [63]. These and later clinical studies confirmed and extended the findings from the aforementioned comparative trials conducted in Edinburgh

Table 2 Comparisons between metformin vs phenformin and buformin

\begin{tabular}{|c|c|c|c|}
\hline Feature & Metformin & Phenformin & Buformin \\
\hline Solubility & $\begin{array}{l}\text { More hydrophilic than phenformin } \\
\text { or buformin }\end{array}$ & $\begin{array}{l}\text { More lipophilic than metformin } \\
\text { or buformin }\end{array}$ & $\begin{array}{l}\text { Intermediate between } \\
\text { metformin and phenformin }\end{array}$ \\
\hline $\log P$ (octanol-water) & -1.43 & -0.83 & -1.20 \\
\hline $\begin{array}{l}\text { Binding to mitochondrial } \\
\text { membranes and inhibition } \\
\text { of respiratory chain }\end{array}$ & Weaker & Stronger & Stronger \\
\hline $\begin{array}{l}\text { Location of anaerobic } \\
\text { glycolysis }\end{array}$ & $\begin{array}{l}\text { Mostly intestinal tissue exposed } \\
\text { to high drug concentration }\end{array}$ & More generalised, including muscle & $\begin{array}{l}\text { More generalised, including } \\
\text { muscle }\end{array}$ \\
\hline Metabolism & $\begin{array}{l}\text { Not metabolised, eliminated } \\
\text { unchanged }\end{array}$ & $\begin{array}{l}\text { About one-third hydroxylated by } \\
\text { CYP2D6 ( 9\% Europids have } \\
\text { CYP2D6 polymorphisms) }\end{array}$ & Almost all eliminated unchanged \\
\hline $\begin{array}{l}\text { Risk of lactic acidosis } \\
\quad \text { (events per } 1000 \text { patient-years) }\end{array}$ & $0.03-0.09$ & $0.40-0.90$ & $>0.10$ \\
\hline
\end{tabular}

Data extracted from [40, 45, 92].

CYP2D6, cytochrome P450 2D6; $P$, partition coefficient 
two decades earlier, and the design of the FDA registration trials for metformin has provided a template for phase 3 evaluation of subsequent glucose-lowering agents [63, 64]. Bristol Myers Squibb acquired US marketing rights to metformin and instigated an education programme of unprecedented proportion to facilitate safe introduction of the drug, emphasising its different mode of action to sulfonylureas and the necessary cautions associated with renal impairment and hypoxaemic conditions. The value of this safety-first approach accorded with the FDA's 'black box warning' reminder that is inserted in the product label and played an important role in maintaining the acknowledged safety profile of the drug [64]. As prescriber confidence grew, an extended-release formulation of metformin was approved in 2000 with reduced gastrointestinal side effects $[65,66]$. Also, new fixed-dose combinations of metformin with sulfonylureas, and later with other classes of oral glucose-lowering agents, became available, taking advantage of additive efficacy when combining agents with different modes of action [67]. The key difference from earlier European fixed-dose combinations was that the dosages were based around metformin as the primary component, with doses of the second agent tailored to complement the administration schedule for metformin and to minimise risk of hypoglycaemia [68].

\section{The UKPDS and long-term retrospective studies}

In 1998, the UKPDS revealed data from newly diagnosed type 2 diabetes individuals receiving glucose-lowering treatment for more than a decade. This epic study, which redefined the therapeutic strategy for the management of type 2 diabetes, noted that in addition to glucose-lowering effects, weight neutrality and low hypoglycaemia risk, long-term metformin therapy might reduce cardiovascular events and improve survival [69]. Reduced cardiovascular risk appeared to be largely independent of glucose-lowering efficacy and attention is drawn to a substantial literature noting potentially advantageous effects of the drug on the macro- and microvasculature (Table 3 ) $[70,71]$. Interrogation of large databases that captured longterm treatment of type 2 diabetes consistently confirmed the reduced cardiovascular risk with metformin, and a 10-year follow-up of the UKPDS in 2008 showed a continued cardiovascular benefit of early use of the drug [72-74].

\section{First-line pharmacological choice}

Many studies on the pharmacokinetics, pharmacodynamics, clinical efficacy and cellular mechanisms of metformin have informed a favourable benefit:risk ratio that, alongside costeffectiveness, has elevated this agent to the preferred first-line glucose-lowering pharmacological therapy for type 2 diabetes in major national and international treatment guidelines and algorithms (for examples, see [75-78]). Metformin has become the most prescribed glucose-lowering therapy worldwide and it is now included in the World Health Organization's (WHO's) essential medicines list [79]. A citizens' petition in the USA prompted an update to the product label in 2016 to extend prescribing for individuals with mild renal impairment. Overall, the prominent position of metformin reflects judicious prescribing, emphasising that contraindications should not be over-relaxed if the safety profile is to be retained (Table 4).

Table 3 Pharmacodynamic effects of metformin in the treatment of type 2 diabetes

\begin{tabular}{|c|c|}
\hline Clinical feature & Effect of metformin \\
\hline Hyperglycaemia & Improves glycaemic control in T2D; reduces progression of IGT and IFG to T2D \\
\hline Insulin resistance & $\begin{array}{l}\text { Counters insulin resistance by several insulin-dependent and -independent actions that reduce hepatic } \\
\text { glucose output, improve peripheral glucose disposal, increase intestinal anaerobic glucose metabolism } \\
\text { and assist endothelial function }\end{array}$ \\
\hline Hyperinsulinaemia & Reduces fasting hyperinsulinaemia \\
\hline Abdominal obesity & Usually stabilises body weight; can facilitate reduction of excess adiposity \\
\hline Dyslipidaemia & $\begin{array}{l}\text { May modestly improve blood lipid profile in some hypertriacylglycerolaemic and hypercholesterolaemic } \\
\text { individuals }\end{array}$ \\
\hline Blood pressure & $\begin{array}{l}\text { No significant effect on blood pressure in most studies but blood pressure control may be improved in } \\
\text { overweight individuals achieving weight loss }\end{array}$ \\
\hline Proinflammatory state & May reduce CRP and some adipocytokines \\
\hline Procoagulant state & $\begin{array}{l}\text { Some antithrombotic activity, e.g. decrease in PAI-1, fibrinogen and platelet aggregation; improved } \\
\text { capillary perfusion }\end{array}$ \\
\hline Atherosclerosis & $\begin{array}{l}\text { Reduced myocardial infarction and increased survival in T2D: reduced carotid intima-media thickness } \\
\text { and reduced levels of adhesion molecules; other evidence for antiatherogenic activity, mostly from } \\
\text { animal studies }\end{array}$ \\
\hline
\end{tabular}

CRP, C-reactive protein; PAI-1, plasminogen activator inhibitor-1; T2D, type 2 diabetes 
Table 4 Clinical use of metformin in the treatment of type 2 diabetes

\begin{tabular}{|c|c|}
\hline Feature & Comment \\
\hline Indications $^{\mathrm{a}}$ & $\begin{array}{l}\text { Monotherapy or in combination with other glucose-lowering agents including insulin in type } 2 \text { diabetes patients } \\
\text { inadequately controlled by diet, exercise, and health education }\end{array}$ \\
\hline Dosage forms ${ }^{b}$ & $\begin{array}{l}500,850 \text { and } 1000 \mathrm{mg} \text { standard (IR) tablets (taken with meals); } \\
500,750 \text { and } 1000 \mathrm{mg} \text { XR tablets (mostly taken with evening meal); } \\
500 \mathrm{mg} / 5 \mathrm{ml} \text { liquid formulation; } \\
500 \mathrm{mg} \text { powder sachets }\end{array}$ \\
\hline Titration & $\begin{array}{l}\text { Increase dose slowly; monitor glycaemic control; maximal dose is } 2550 \text { or } 3000 \mathrm{mg} / \mathrm{day} \text {, depending on country } \\
\text { (2000 mg/day in children) }\end{array}$ \\
\hline Contraindications $^{\mathrm{a}}$ & $\begin{array}{l}\text { Renal and hepatic disease; cardiac or respiratory insufficiency; any hypoxic condition; severe infection; alcohol } \\
\text { abuse; history of lactic acidosis; temporarily discontinue during use of i.v. radiographic contrast agents; pregnancy } \\
\text { (although safe use is demonstrated in several studies) } \\
\text { N.B. Some guidelines have relaxed the renal contraindication and suggest: reduce metformin dose in renal impairment } \\
\text { if eGFR }<60 \mathrm{ml} / \mathrm{min} / 1.73 \mathrm{~m}^{2} \text { (MDRD); avoid initiating metformin if eGFR }<45 \mathrm{ml} / \mathrm{min} / 1.73 \mathrm{~m}^{2} \text {; stop metformin if } \\
\text { eGFR }<30 \mathrm{ml} / \mathrm{min} / 1.73 \mathrm{~m}^{2}\end{array}$ \\
\hline Side effects & $\begin{array}{l}\text { Gastrointestinal symptoms (may include diarrhoea) and metallic taste, likely to improve with dose reduction and } \\
\text { re-titration; may impair absorption of vitamin } \mathrm{B}_{12} \text { and folic acid }\end{array}$ \\
\hline Adverse reactions & $\begin{array}{l}\text { Risk of lactic acidosis in patients with a contraindication; hypoglycaemia can occur when taken in combination } \\
\text { with another glucose-lowering drug or during alcohol abuse }\end{array}$ \\
\hline Monitoring & $\begin{array}{l}\text { Check for contraindications; check plasma creatinine level or eGFR and haemoglobin periodically; possible } \\
\text { interaction with cimetidine therapy }\end{array}$ \\
\hline
\end{tabular}

The information in this table is based on the approved labelling of metformin by the FDA and European Medicines Agency (EMA), and recommendations of the National Institute for Health and Care Excellence (NICE) in the UK.

${ }^{\mathrm{a}}$ The exact wording of indications and contraindications varies according to the labelling approved in different countries and regional and national guidelines

${ }^{\mathrm{b}}$ Dose and formulation varies depending on country

eGFR, estimated glomerular filtration rate; IR, immediate-release; MDRD, modification of diet in renal disease; XR, extended-release/slow-release

\section{Other indications}

Possible additional indications for metformin are under investigation; opportunities for its use in type 1 diabetes to improve glycaemic control and reduce required insulin dose have been appreciated since the very first clinical studies [6, 80]. Several studies have affirmed the value of metformin to slow or prevent progression of impaired glucose tolerance (IGT)/impaired fasting glucose (IFG) ('prediabetes') to type 2 diabetes and other studies have suggested a place for metformin in the

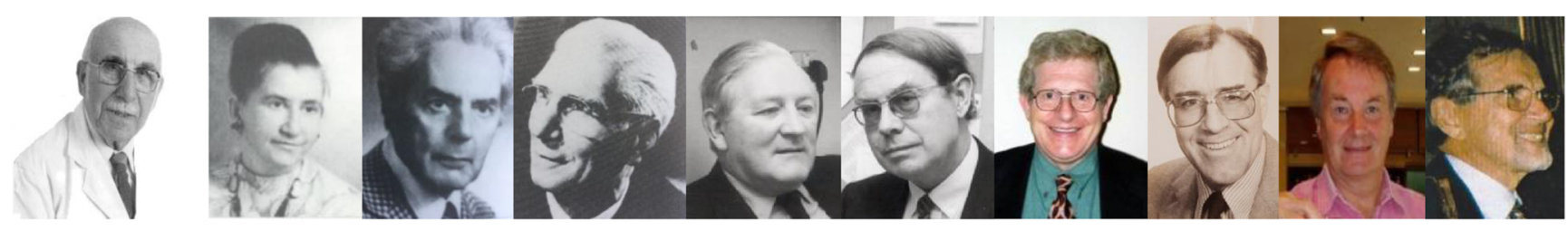

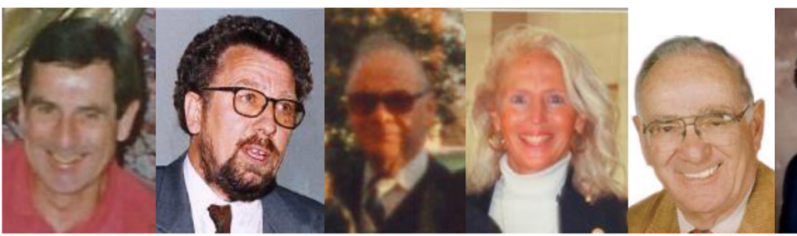

Fig. 5 Gallery of people who 'made metformin happen'. Upper row: Jean Sterne, Denise Duval, Jan Aron, Elie Azerad, Leslie Duncan, Basil Clarke, Ian Campbell, Leif Sparre Hermann, Harry Howlett, Michel Noel. Lower row: Andre Meynaud, Nicolas Wiernsperger, Gerard Daniel, Anita Goodman, Gerald Reaven, Ralph DeFronzo, Clifford Bailey, Robert Turner, Alan Garber, Dennis Cryer, Rury Holman.

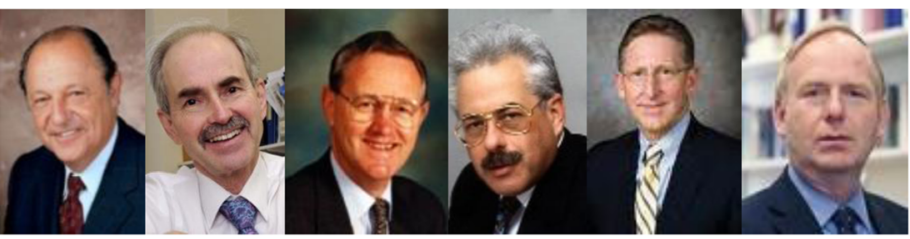

Missing: C. K. Watanabe, Emil Werner and James Bell, Erich Hesse and Gert Taubmann, Karl Slotta and Rudolf Tschesche, Eusebio Garcia. Apologies to the thousands of scientists, healthcare professionals and pharmaceutical personnel listed in reference [56] who have made important contributions to the journey of metformin but who have not been listed here. Copyright for each photograph lies with the respective holders 
treatment of gestational diabetes [81-83]. Various insulinresistant states in which metformin has improved prognosis include polycystic ovary syndrome (PCOS), human immunodeficiency virus (HIV)-associated lipodystrophy, acanthosis nigricans and, possibly, dementia-type neurodegenerative disorders [84-87]. Reduced cancer risk was tentatively indicated in the UKPDS and has subsequently been identified in large database analyses, suggesting that metformin might protect against certain cancers in individuals with type 2 diabetes, notably in the bowel where drug exposure is high, and this has opened a whole new research arena $[69,88,89]$. Advances in pharmacogenomics may better inform responsiveness to metformin and effects on the gut microbiome, and animal studies have intriguingly noted anti-ageing effects of metformin $[90,91]$.

\section{Some lessons}

There are endless generic lessons for medical research thinly disguised within the history of metformin. With hindsight, we are reminded that time spent searching early original literature can save valuable laboratory time, effort and money: vital clues can be concealed amidst throw-away observations in other areas of research. We are also reminded that the selection and interpretation of experimental models is fundamental, scrutiny within a drug class can reveal important differences, and we don't have to know exactly how a drug works to reap benefit, but we do need to appreciate how to use it safely.

\section{Conclusion}

The awesome voyage of metformin from herbal beginnings to respected therapeutic agent has been turbulent. It was discovered, forgotten, rediscovered, repurposed, rejected, rescued, exonerated and may have further secrets to reveal. Each chapter has a cast of champions who helped it on its way (Fig. 5), but the pivotal work of Jean Sterne stands aloft [6, 56]. Metformin is unusual amongst pharmacotherapies as it does not appear to have a single mechanistic target: rather it counters insulin resistance and impacts metabolic, vascular and other physiological functions through multiple effects that are individually modest but collectively substantial. The value of such a favourably versatile medication requires that the contraindications (especially renal and hypoxaemic restrictions) are respected and that further potential therapeutic opportunities are explored.

Funding This work received no specific grant from any funding agency in the public, commercial or not-for-profit sectors'.
Duality of interest The author declares that there is no duality of interest associated with this manuscript.

Contribution statement The author was the sole contributor to this paper.

\section{References}

1. Bailey CJ, Day C (2004) Metformin: its botanical background. Pract Diabetes Int 21:115-117

2. Culpeper N (1995) Culpeper's complete herbal: a book of natural remedies for ancient ills. Wordsworth Editions Ltd, Ware, Hertfordshire p335. Available from https://books.google.co.uk/ books?id=aGih_JZtPvoC\&pg=PA335\&lpg=PA335\&dq=galega + culpeper+herbal\&source $=$ bl\&ots $=77 \mathrm{gExCABa} \& \mathrm{sig}=$ wV0BcjUm RS8F6ZRMjo8N8F6zgU\&hl=en\&sa $=\bar{X} \& v e d=$ 0ahUKEwiPw fJ6YzSAhUBJcAKHV4EB2kQ6AEIQTAH\#v= onepage $\& \mathrm{q}=$ galega $\% 20$ culpeper $\% 20$ herbal $\& \mathrm{f}=$ false. Accessed 13 Feb 2017

3. Hill J (1772). The vegetable system. Or the internal structure and the life of plants; their parts, and nourishment, explained; their classes, orders, genera, and species, ascertained, and described; in a methods altogether new: comprehending an artificial index, and a natural system. With figures of all the plants; designed and engraved by the author. The whole from nature only. Vol. XXI, containing plants and four-petal'd irregular flowers. London, p54

4. Hadden DR (2005) Goat's rue - French lilac - Italian fitch Spanish sainfoin: gallega officinalis and metformin: the Edinburgh connection. J R Coll Physicians Edinb 35:258-260

5. Galega officinalis. Available from https://en.wikipedia.org/wiki/ Galega_officinalis. Accessed 27 Feb 2017

6. Pasik C (1997) Diabetes and the biguanides: the mystery of each. In: Pasik C (ed) Glucophage: serving diabetology for 40 years. Groupe Lipha, Lyon, p79

7. Watanabe CK (1918) Studies in the metabolic changes induced by administration of guanidine bases. Influence of injected guanidine hydrochloride upon blood sugar content. J Biol Chem 33:253-265

8. Frank E, Nothmann M, Wagner A (1926) Über synthetisch dargestellte Körper mit insulinartiger Wirkung auf den normalen und diabetischen Organismus. Klin Wchnschr 5:2100-2107 [article in German]

9. Simonnet H, Tanret G (1927). Sur les proprietes hypoglycemiantes du sulfate de galegine. Bull Soc Chim Biol Paris, 8 [article in French]

10. Bischoff F, Sahyun M, Long ML (1928) Guanidine structure and hypoglycemia. J Biol Chem 81:325-349

11. Muller H, Reinwein H (1927) Zur Pharmakologie des Galegins. Arch Exp Path Pharmacol 125:212-228 [article in German]

12. Rabinowiz IM (1927) Observations on the use of synthalin in the treatment of diabetes mellitus. Can Med Assoc J 17:901-904

13. Leclerc H. Le galega. Presse Med 1928, 22 décembre [article in French]

14. Howlett HCS, Bailey CJ (2007) Galegine and antidiabetic plants In: Bailey CJ, Campbell IW, JCN C et al (eds) Metformin — the gold standard: a scientific handbook. Wiley, Chichester, pp 3-9

15. Parturier H, Hugnot G (1935). Le galega dans le traitement du diabète. Massons, Paris [article in French]

16. Rathke B (1879) Uber Biguanid. Ber Dtsch Chem Ges 12:776-784 [article in German]

17. Werner EA, Bell J (1922) The preparation of methylguanidine, and of $\beta \beta$-dimethylguanidine by the interaction of dicyandiamide, and methylammonium and dimethylammonium chlorides respectively. J Chem Soc Trans 121:1790-1794 
18. Hesse G, Taubmann G (1929) Die Wirkung des Biguanids und seiner Derivate auf den Zuckerstoffwechsel. Arch Exp Path Pharmacol 142:290-308 [article in German]

19. Slotta KH, Tschesche R (1929) Uber Biguanide. Die blutzuckersenkende Wirkung der Biguanides. Ber Dtsch Chem Ges 62:1398-1405 [article in German]

20. Curd FHS, Davey DG, Rose FL (1945) Studies on synthetic antimalarial drugs. Some biguanide derivatives as new types of antimalarial substances with both therapeutic and causal prophylactic activity. Ann Trop Med Parasitol 39:208-216

21. Chen KK, Anderson RC (1947) The toxicity and general pharmacology of N1-p-chlorophenyl-N5-isopropyl biguanide. J Pharmacol Exp Ther 91:157-160

22. Garcia EY (1950) Flumamine, a new synthetic analgesic and antiflu drug. J Philippine Med Assoc 26:287-293

23. Pasik C (1997) Jean Sterne: a passion for research. In: Pasik C (ed) Glucophage: serving diabetology for 40 years. Lyon, Groupe Lipha, pp 29-31

24. Sterne J (1957) Du nouveau dans les antidiabétiques. La NN dimethylamine guanyl guanidine (N.N.D.G.) Maroc Med 36: 1295-1296 [article in French]

25. Sterne J (1958) Blood sugar-lowering effect of 1,1dimethylbiguanide. Therapie 13:650-659 article in French

26. Sterne J (1959) Treatment of diabetes mellitus with N,Ndimethylguanylguanidine (LA. 6023, glucophage). Therapie 14: 625-630 [article in French]

27. Sterne J (1963) Report on 5-years' experience with dimethylbiguanide (metformin, glucophage) in diabetic therapy. Wien Med Wochenschr 113:599-602 [article in German]

28. Sterne J, Hirsch C (1964) Experimental basis for combined treatment of diabetes with the biguanide-sulfonamide association. Diabete 12:171-175 [article in French]

29. Sterne J (1964) Mechanism of action of antidiabetic biguanides. Presse Med 72:17-19 [article in French]

30. Sterne J (1969) Pharmacology and mode of action of the hypoglycemic guanidine derivatives. In: Campbell GD (ed) Oral hypoglycemic agents. Academic Press, London, pp 193-245

31. Sterne J, Duval D, Junien JL (1979). Aspects of pharmacology and mechanisms of action. In: Cudwoth AG (ed) Metformin: current aspects and future developments. Research and Clinical Forums, Vol. 1, Tunbridge Wells, pp 13-20

32. Ungar G, Freedman L, Shapiro SL (1957) Pharmacological studies of a new oral hypoglycemic drug. Proc Soc Exp Biol Med 95:190 192

33. Beringer A (1958) Zur Behandlung der Zuckerkrankheiten mit Biguaniden. Wien Med Wschr 108:880-882 [article in German]

34. Shapiro SL, Parrino VA, Freedman L (1959) Hypoglycemic agents. III. ${ }^{1-3}$ N1-alkyl- and aralkylbiguanides. J Am Chem Soc 81:37283736

35. Beckmann R (1971) Biguanide (Experimenteller Teil). Handb Exp Pharmacol 29:439-596 [article in German]

36. Azerad E, Lubetzki J (1959) Treatment of diabetes with N,N-dimethyl diguanide (LA6023). Presse Med 67:765-767 [article in French]

37. McKendry JB, Kuwayti K, Rado PP (1959) Clinical experience with DBI (phenformin) in the management of diabetes. Can Med Assoc J 80:773-778

38. Mehnert H, Seitz W (1958) Weitere Ergebnisse der Diabetesbehandlung mit blutzuckersenkenden Biguaniden. Münch Med Wochenschr 100:1849-1851 [article in German]

39. Butterfield WJ (1968) The effects of phenformin on peripheral glucose utilization and insulin action in obesity and diabetes mellitus. Ann N Y Acad Sci 148:724-733

40. Schäfer G (1983) Biguanides: a review of history, pharmacodynamics and therapy. Diabete Metab 9:148-163
41. Hermann LS (1979) Metformin: a review of its pharmacological properties and therapeutic use. Diabete Metab 5:233-245

42. Clarke BF, Duncan LJP (1968) Comparison of chlorpropamide and metformin treatment on weight and blood-glucose response of uncontrolled obese diabetics. Lancet 291:123-126

43. Clarke B, Campbell IW (1977) Comparison of metformin and chlorpropamide in non-obese maturity-onset diabetic uncontrolled on diet. Br Med J 275:1576-1578

44. Campbell IW, Howlett HC (1995) Worldwide experience of metformin as an effective glucose-lowering agent: a meta-analysis. Diabetes Metab Res Rev 11(Suppl 1):S57-S62

45. Bailey CJ (1992) Biguanides and NIDDM. Diabetes Care 15:755772

46. Walker RS, Linton AL (1959) Phenethylbiguanide: a dangerous side effect. Br Med J 2:1005-1006

47. Luft D, Schmulling RM, Eggstein M (1978) Lactic acidosis in biguanide-treated diabetics. Diabetologia 14:75-87

48. University Group Diabetes Program (1975) A study of the effects of hypoglycemic agents on vascular complications in patients with adult-onset diabetes. Evaluation of phenformin therapy. Diabetes 24(Suppl 1):65-184

49. Nattrass M, Alberti KGMM (1978) Biguanides. Diabetologia 14: 71-74

50. Bailey CJ, Nattrass M (1988) Treatment-metformin. Ballière's Clin Endocrinol Metab 2:455-476

51. Lalau JD (2010) Lactic acidosis induced by metformin: incidence, management and prevention. Drug Saf 33:727-740

52. Shah RR, Oates NS, Idle JR, Smith RL (1980) Genetic impairment of phenformin metabolism. Lancet 315:1147

53. Bosisio E, Kienle MG, Galli G et al (1981) Defective hydroxylation of phenformin as a determinant of drug toxicity. Diabetes 30:644 649

54. DeFronzo RA (1988) The triumvirate: $\beta$-cell, muscle, liver: a collusion responsible for NIDDM. Diabetes 37:667-687

55. Reaven GM (1988) Role of insulin resistance in human disease. Diabetes 37:1595-1607

56. Howlett HCS, Bailey CJ (2007) Metformin: a chemical perspective. In: Bailey CJ, Campbell IW, Chan JCN et al (eds) Metformin, the gold standard. A scientific handbook. Wiley, Chichester, pp 23-28

57. Bailey CJ, Puah JA (1986) Effect of metformin on glucose metabolism in mouse soleus muscle. Diabete Metab 12:212-218

58. Wollen N, Bailey CJ (1988) Inhibition of hepatic gluconeogenesis by metformin: synergism with insulin. Biochem Pharmacol 37: $4353-4358$

59. Bailey CJ, Wilcock C, Day C (1992) Effect of metformin on glucose metabolism in the splanchnic bed. Br J Pharmacol 105:10091013

60. Wilcock C, Bailey CJ (1994) Accumulation of metformin by tissues of the normal and diabetic mouse. Xenobiotica 24:49-57

61. Bailey CJ, Mynett KJ, Page T (1994) Importance of the intestine as a site of metformin-stimulated glucose utilization. Brit J Pharmacol 112:671-675

62. Wiernsperger NF, Bailey CJ (1999) The antihyperglycaemic effect of metformin: therapeutic and cellular mechanisms. Drugs 58(Suppl 1):31-39

63. DeFronzo RA, Goodman AM, Multicenter Metformin Study Group (1995) Efficacy of metformin in patients with non-insulindependent diabetes mellitus. N Engl J Med 333:541-549

64. Bailey CJ, Turner RC (1996) Drug therapy: metformin. N Engl J Med 334:574-579

65. Blonde L, Dailey GE, Jabbour SA, Reasner CA, Mills DJ (2004) Gastrointestinal tolerability of extended-release metformin tablets compared to immediate-release metformin tablets - results of a retrospective cohort study. Curr Med Res Opin 20:565-572 
66. Davidson J, Howlett H (2004) New prolonged-release metformin improves gastrointestinal tolerability. Br J Diabetes Vasc Dis 4: 273-277

67. Garber AJ, Larsen J, Schneider SH, Piper BA, Henry D (2002) Simultaneous glyburide/metformin therapy is superior to component monotherapy as an initial pharmacological treatment for type 2 diabetes. Diabetes Obes Metab 4:201-208

68. Bailey CJ, Day C (2009) Fixed-dose single tablet antidiabetic combinations. Diabetes Obes Metab 11:527-533

69. UK Prospective Diabetes Study (UKPDS) Group (1998) Effect of intensive blood glucose control with metformin on complications in overweight patients with type 2 diabetes (UKPDS 34). Lancet 352: 854-865

70. Wiernsperger NF (2007) 50 years later: is metformin a vascular drug with antidiabetic properties? Br J Diabetes Vasc Dis 7:204 210

71. Bailey CJ (2008) Metformin: effects on micro and macrovascular complications in type 2 diabetes. Cardiovasc Drug Ther 22:215224

72. Johnson JA, Simpson SH, Toth EL, Majumdar SR (2005) Reduced cardiovascular morbidity and mortality associated with metformin use in subjects with type 2 diabetes. Diabet Med 22:497-502

73. Eurich D, Majumdar SR, FA MA, Tsuyuki RT, Johnson JA (2005) Improved clinical outcomes associated with metformin in patients with diabetes and heart failure. Diabetes Care 28:2345-2351

74. Holman RR, Paul SK, Bethel MA, Matthews DR, Neil HAW (2008) 10-year follow-up of intensive glucose control in type 2 diabetes. N Engl J Med 359:1577-1589

75. International Diabetes Federation Clinical Guidelines Task Force (2012). Global guideline for type 2 diabetes. Available from www.idf.org/e-library/guidelines/79-global-guideline-for-type-2diabetes. Accessed 10 May 2017

76. Inzucchi SE, Bergenstal RM, Buse JB et al (2015) Management of hyperglycemia in type 2 diabetes, 2015: a patient-centered approach: update to a position statement of the American Diabetes Association and the European Association for the Study of diabetes. Diabetologia 58:429-442

77. Garber AJ, Abrahamson MJ, Barzilay JI et al (2017) Consensus statement by the American Association of Clinical Endocrinologists and American College of Endocrinology on the comprehensive type 2 diabetes management algorithm-2017 executive summary. Endocr Pract 23:207-238
78. Qaseem A, Barry MJ, Humphrey LL, Forciea MA for the Clinical Guidelines Committee of the American College of Physicians (2017) Oral pharmacologic treatment of type 2 diabetes mellitus: a clinical practice guideline update from the American College of Physicians. Ann Intern Med 166:279-290

79. World Health Organization (2015). WHO model list of essential medicines. Available from www.who.int/medicines/publications/ essentialmedicines/EML 2015 FINAL_amended NOV2015.pdf? ua=1. Accessed 10 Feb 2017

80. Ferguson AW, De La Harpe PL, Farquhar JW (1961) Dimethyl biguanide in the treatment of diabetic children. Lancet 1:13671369

81. Knowler WC, Barrett-Connor E, Fowler SE et al (2002) Reduction in the incidence of type 2 diabetes with lifestyle intervention or metformin. N Engl J Med 346:393-403

82. Hostalek U, Gwilt M, Hildemann S (2015) Therapeutic use of metformin in prediabetes and diabetes prevention. Drugs 75:10711094

83. Rowan JA, Hague WM, Gao W, Battin MR, Moore MP for the MiG Trial Investigators (2008) Metformin versus insulin for the treatment of gestational diabetes. N Engl J Med 358:2003-2015

84. Nestler JE (2008) Metformin for the treatment of the polycystic ovary syndrome. N Engl J Med 358:47-54

85. Hadigan C, Corcoran C, Basgoz N, Davis B, Sax P, Grinspoon S (2000) Metformin in the treatment of HIV lipodystrophy syndrome: a randomized controlled trial. JAMA 284:472-477

86. Tankova T, Koev D, Dakovska L, Kirilov G (2002) Therapeutic approach in insulin resistance with acanthosis nigricans. Int $\mathrm{J}$ Clin Pract 56:578-581

87. Moreira PI (2014) Metformin in the diabetic brain: friend or foe? Ann Transl Med 2:54

88. Evans JM, Donnelly LA, Emslie-Smith AM, Alessi DR, Morris AD (2005) Metformin and reduced risk of cancer in diabetic patients. BMJ 330:1304-1305

89. Currie CJ, Poole CD, Gale EA (2009) The influence of glucoselowering therapies on cancer risk in type 2 diabetes. Diabetologia 52:1766-1777

90. Barzilai N, Crandall JP, Kritchevsky SB, Espeland MA (2016) Metformin as a tool to target aging. Cell Metab 23:1060-1065

91. McCreight LJ, Bailey CJ, Pearson ER (2016) Metformin and the gastrointestinal tract. Diabetologia 59:426-435

92. Scheen AJ (1996) Clinical pharmacokinetics of metformin. Clin Pharm 30:359-371 